\title{
Salmonella enterica: isolamento e soroprevalência em suínos abatidos no Rio Grande do Sul
}

[Salmonella enterica: isolation and seroprevalence in swines slaughtered in Rio Grande do Sul]

P. Schwarz, J. Calveira, A. Sella, M. Bessa, D.E.S.N. Barcellos, M. Cardoso*

Faculdade de Veterinária - UFRGS

Av. Bento Gonçalves, 9090

91450-000 - Porto Alegre, RS

\begin{abstract}
RESUMO
Estudou-se a prevalência de Salmonella spp. em suínos ao abate e compararam-se os resultados obtidos no isolamento e na sorologia de modo a determinar a fase mais importante de infecção (granja ou transporte/espera pré-abate) em relação ao número de suínos portadores encontrados ao abate. Foram avaliados 40 rebanhos de três diferentes empresas do sul do Brasil, com colheitas de sangue e linfonodos mesentéricos de 20 animais por lote. O soro foi submetido ao ELISA produzido com antígeno somático de Salmonella Typhimurium. A frequência de isolamento variou de $62,5 \%$ a $85,0 \%$, enquanto a soroprevalência de $73,8 \%$ a $83,2 \%$ nos três sistemas amostrados. Os sorovares mais prevalentes foram Agona, Typhimurium e Panama. A infecção dos animais ocorreu nas granjas produtoras de suínos nestes sistemas de produção, pois os lotes apresentaram elevada soroprevalência ao abate. Concluiu-se que o controle da infecção por Salmonella spp. no sul do Brasil deve iniciar-se pela implementação de medidas de profilaxia nas granjas de produção de suínos.
\end{abstract}

Palavras-chave: suíno, Salmonella, prevalência, isolamento, sorologia

\begin{abstract}
The prevalence of Salmonella in slaughtered swines was evaluated and the results of serology and Salmonella isolation were compared to determine the most important stage of the infection (on-farm or transport and pre-slaughter) in relation to the number of carrier animals found at slaughter. Forty herds from three different swine raisers of the southern region of Brazil were sampled at slaughter. Blood and mesenteric lymph nodes were collected from 20 swines of each herd. Serum samples were submitted to ELISA including somatic antigens of S. Typhimurium. Salmonella was isolated from $62.5 \%$ to $85.0 \%$ of the animals, while seroprevalence varied from $73.8 \%$ to $83.2 \%$ in the three swine raisers. Serovar Agona, Typhimurium, and Panama were the most prevalent among the Salmonella isolates. Isolation and serological results demonstrated that Salmonella infection occurred during the on-farm stage, since a high seroprevalence was detected at slaughter. It was concluded that a Salmonella control program in southern Brazil must be started with the implementation of intervention measures at farm level.
\end{abstract}

Keywords: swine, Salmonella, prevalence, slaughter, source infection

\section{INTRODUÇ̃̃̃O}

$\mathrm{Na}$ Dinamarca, o registro de casos de salmonelose em humanos associados ao consumo de produtos de origem suína (Wegener e Baggesen, 1997) determinou a implementação do programa de monitoramento e controle dos rebanhos, que tem sido modelo para ações semelhantes em outros países produtores e exportadores de carne suína (Mousing et al., 1997; van Altrock et al., 2000).

Recebido em 10 de dezembro de 2008

Aceito em 9 de setembro de 2009

* Autor para correspondência (corresponding author)

E-mail: mcardoso@ufrgs.br 
A associação de dados de prevalência sorológica e de isolamento de Salmonella sp., base do monitoramento dos rebanhos, tem sido útil para a identificação de fatores de risco para a infecção em lotes de suínos (Mousing et al., 1997; van der Wolf et al., 2001; Lo Fo Wong et al., 2004). Os resultados obtidos em testes sorológicos indicam exposição prévia à Salmonella sp. (Nielsen et al., 1995). As amostras de conteúdo intestinal e linfonodos mesentéricos, submetidas a protocolos de isolamento, demonstram a presença de Salmonella sp. no trato gastrintestinal dos animais (Lo Fo Wong et al., 2004).

A infecção de suínos por Salmonella sp. pode ocorrer nas granjas produtoras, durante $\mathrm{o}$ transporte e nas baias de espera dos frigoríficos (Swanenburg et al., 2001). Consequentemente, diferentes etapas da cadeia de produção de suínos devem ser monitoradas, para que seja possível a implementação de medidas de controle em pontos críticos.

No sul do Brasil, no ano de 2000, Bessa et al. (2004) relataram que 55,6\% dos suínos abatidos apresentavam Salmonella sp. em linfonodos e conteúdo intestinal. Posteriormente, o desenvolvimento de um ELISA indireto, baseado no antígeno lipopolissacarídeo do sorovar Typhimurium (Kich et al., 2007), possibilitou a determinação de soroprevalência (Kich et al., 2005), em que 55,7\% dos lotes de terminação uma semana antes da remessa para o abate eram positivos, indicando que a infecção dos rebanhos da região provavelmente já ocorria na granja. Entretanto, ainda não foi estudada a associação entre sorologia e isolamento dos lotes amostrados, de modo a caracterizar a origem (granja ou espera pré-abate) das infecções.

A partir disso, o presente estudo teve os objetivos de associar a pesquisa de anticorpos e o isolamento de Salmonella sp. em lotes de suínos abatidos no Estado do Rio Grande do Sul e determinar a prevalência de suínos portadores de Salmonella sp. ao abate e a provável origem da infecção.

\section{MATERIAL E MÉTODOS}

O trabalho foi realizado no período de junho a novembro de 2005, em três matadourosfrigoríficos sob Inspeção Federal, localizados no
Rio Grande do Sul. Dois estabelecimentos pertenciam a agroindústrias (sistemas A e B) que abatiam diariamente cerca de 2800 suínos, provenientes de produtores do sistema de integração vertical. $O$ terceiro pertencia a uma cooperativa (sistema $\mathrm{C}$ ) que abatia diariamente em torno de 750 suínos entregues por produtores associados e independentes.

Foram amostrados 800 animais pertencentes a 40 lotes provenientes de granjas distintas, representando diferentes condições de manejo produtivo, situação sanitária, linhagens genéticas e origem dos animais. Apenas suínos terminados foram examinados, não sendo amostrados lotes de leitões refugo, de reprodutores de descarte e de abates de emergência. As amostragens foram realizadas a cada quatro dias para permitir maior variabilidade de produtores, e todos os lotes abatidos no dia eram amostrados.

Em cada lote, foram colhidas 20 amostras de linfonodos mesentéricos da porção ilíaca do intestino delgado e 20 amostras de sangue. O número de amostras foi calculado, considerandose a população de 200 animais/lote de terminação, prevalência esperada de 50\% (Bessa et al., 2004; Kich et al., 2005), precisão relativa de $40 \%$ e intervalo de confiança de $95 \%$. O material foi identificado conforme o lote de origem e enviado ao laboratório, sob refrigeração.

Os linfonodos mesentéricos foram processados individualmente adotando-se a metodologia de Michael et al. (2003); 25g da amostra foram préenriquecidas em água peptonada tamponada $1 \%$, seguidos de enriquecimento seletivo ${ }^{1} \mathrm{e}$ isolamento em ágar verde brilhante lactosesacarose $^{2}$ e XLT4 ${ }^{3}$. A seguir, colônias típicas selecionadas foram submetidas à confirmação por testes bioquímicos e aglutinação com soro polivalente somático ${ }^{4}$. Os isolados confirmados como Salmonella sp. foram encaminhados para sorotipificação na Fundação Instituto Oswaldo Cruz.

O sangue colhido foi centrifugado para separação do soro que foi submetido ao ELISA indireto

${ }^{1}$ Caldos Rappaport -Vassiliadis e Tetrationato - Merck, Darmstadt, Alemanha.

${ }^{2}$ BPLS - Merck, Darmstadt, Alemanha.

${ }^{3}$ Difco, Sparks, Maryland, EUA.

${ }^{4}$ Probac, São Paulo, Brasil. 
para pesquisa de IgG anti-Salmonella (Kich et al., 2007). Os resultados das análises microbiológica e sorológica foram analisados por estatística descritiva e teste $\mathrm{t}$ para variâncias iguais (SPSS 12.0, 2003).

\section{RESULTADOS E DISCUSSÃO}

A prevalência de suínos positivos no isolamento de Salmonella sp. ao abate foi $71,6 \%$ (intervalo de confiança ( $\mathrm{IC}=70,0-73,2)$ e a soroprevalência $77,8 \% \quad(\mathrm{IC}=76,3-79,3)$, com variação da frequência entre os frigoríficos amostrados (Tab. 1). As frequências de isolamento encontradas ao abate foram mais altas que as encontradas na Alemanha (3,3\%), no meio-oeste dos Estados Unidos (14,9\%), em Portugal (26,7\%), na Tailândia (28\%) e no Mato Grosso, Brasil (Käsbohrer et al., 2000; Bahnson et al., 2005; Vieira-Pinto et al., 2005; Padungtod e Kaneene, 2006; Silva et al., 2008).

A associação entre sorologia e isolamento de Salmonella em suínos abatidos também foi investigada na Holanda (Swanenburg et al., 2001), onde foram encontrados $18 \%$ e 10,9\%, respectivamente, de soroprevalência e frequência de isolamento. Na Grã-Bretanha, foi referido o isolamento de Salmonella sp. das fezes de 23\% dos suínos amostrados ao abate e a soroprevalência de $15,2 \%$ no mesmo grupo de animais (Davies et al., 2004).

Na mesma região do sul do Brasil, já haviam sido observados 55,6\% de animais abatidos positivos em linfonodos mesentéricos e/ou conteúdo intestinal (Bessa et al., 2004). A maior prevalência de isolamento encontrada no presente trabalho indica que persiste a transmissão de Salmonella sp. ao longo da cadeia produtiva de suínos. Por outro lado, a variabilidade na frequência de isolamento em duas investigações realizadas na mesma região está de acordo com resultados obtidos em granjas amostradas em estudos longitudinais por Harris (2003) e Lo Fo Wong et al. (2004). Essa variabilidade demonstra que a cadeia de transmissão de Salmonella sp. é dinâmica, podendo um lote de animais portadores introduzido na granja ou uma partida de ração contaminada influir diretamente na amplificação do número de animais infectados ao longo da cadeia de produção e ao abate (Berends et al., 1996; Silva et al., 2006)
A complexidade da cadeia de transmissão de Salmonella em suínos fica evidente também no perfil dos sorovares isolados nos lotes abatidos. A frequência de isolamento (Tab. 1) demonstra que os lotes, geralmente, estavam infectados por múltiplos sorovares. Ainda, o perfil e a frequência de sorovares isolados foram peculiares ao sistema de produção, refletindo uma epidemiologia própria do sistema vertical de produção de suínos, em que pontos comuns de transmissão (ração, origem dos animais, transporte, entre outros) estão presentes. Essa variabilidade também está refletida ao longo do tempo numa região, sistema de produção ou granja. Dessa forma, enquanto no ano de 2000 os sorovares Typhimurium, Bredeney e Agona eram os mais frequentes nessa região (Bessa et al., 2004), no presente estudo Agona, Typhimurium e Panama foram os mais isolados.

A frequência de isolamento, por si só, não informa sobre a fase em que ocorreu a infecção dos animais. Apesar de programas de monitoramento e controle terem sido principalmente direcionados para as fases de recria e terminação dos suínos (Mousing et al., 1997), estudos posteriores demonstraram que o contato com o ambiente contaminado na espera pré-abate pode contribuir com um grande número de isolamentos de Salmonella sp. na linha de abate (Hurd et al., 2001; Rostagno et al., 2003). A partir desses resultados e considerando que Salmonella sp. pode invadir o íleo em duas horas após a transmissão fecal-oral (Hurd et al., 2001), o período de espera pré-abate passou a ser considerado como um fator de risco importante, principalmente em situações em que o programa de controle instituído na granja já apresentava resultados positivos. $\mathrm{Na}$ Dinamarca, por exemplo, passou-se a adotar uma espera de até duas horas antes do abate (Alban e Stark, 2005). Entretanto, essa medida não pode ser proposta em todos os países, quer seja pela distância entre a granja e o frigorífico, quer seja pelo tempo de descanso previsto na legislação.

A partir disso, torna-se importante a análise dos resultados de soroprevalência para a avaliação do nível de exposição a que os animais são submetidos na granja de origem. Uma vez que um intervalo de pelo menos 14 dias é necessário até que um título de IgG detectável pelo ELISA seja alcançado (Nielsen et al., 1995), a soroprevalência constitui um dado histórico do 
lote proveniente de uma determinada granja (Lo Fo Wong et al., 2004). No presente estudo, a soroprevalência encontrada ao abate (Tab. 1) indica que os animais tiveram uma pressão de infecção elevada na granja de origem, o que está de acordo com os resultados obtidos previamente por Kich et al. (2005), em que 55,7\% dos suínos de terminação, amostrados na última semana de alojamento em 65 granjas do sul do Brasil, foram positivos no ELISA.

Tabela 1. Prevalência de suínos positivos sorologicamente e no isolamento de Salmonella sp. em três matadouros-frigoríficos do Rio Grande do Sul, 2005

\begin{tabular}{|c|c|c|c|c|c|}
\hline \multirow[b]{2}{*}{$\begin{array}{l}\text { Matadouro- } \\
\text { frigorífico }\end{array}$} & \multirow[b]{2}{*}{$\begin{array}{l}\text { Número de } \\
\text { lotes }\end{array}$} & \multirow[b]{2}{*}{$\begin{array}{l}\text { Número } \\
\text { de } \\
\text { animais }\end{array}$} & \multicolumn{2}{|c|}{ Prevalência (\%) } & \multirow[b]{2}{*}{$\begin{array}{l}\text { Sorovares isolados } \\
\text { (número de lotes) }\end{array}$} \\
\hline & & & $\begin{array}{l}\text { Sorologia } \\
\text { (Mínimo- } \\
\text { Máximo) }\end{array}$ & $\begin{array}{l}\text { Isolamento } \\
\text { (Mínimo- } \\
\text { Máximo) }\end{array}$ & \\
\hline A & 14 & 280 & $\begin{array}{c}73,8 \\
(20-95)\end{array}$ & $\begin{array}{c}72,0 \\
(45-95)\end{array}$ & $\begin{array}{ll}\text { Agona (7), Ohio (6), } \\
\text { Panama (6), Derby } & (4), \\
\text { Schwarzengrund } & (3), \\
\text { Bovismorbificans } & (1), \\
\text { Cubana } & (1), \\
\text { Typhimurium (1) }\end{array}$ \\
\hline $\mathrm{B}$ & 14 & 280 & $\begin{array}{c}77,8 \\
(21-96)\end{array}$ & $\begin{array}{c}85,0 \\
(60-100)\end{array}$ & $\begin{array}{l}\text { Brandenburg } \\
\text { Typhimurium (13), } \\
\text { Agona (6), Derby (4), } \\
\text { Panama } \\
\text { Worthington (3), } \\
\text { Ohio (2) }\end{array}$ \\
\hline $\mathrm{C}$ & 12 & 240 & $\begin{array}{c}83,2 \\
(50-100)\end{array}$ & $\begin{array}{c}62,5 \\
(27-87)\end{array}$ & $\begin{array}{l}\text { Typhimurium (10), } \\
\text { Agona (9), Panama (6), } \\
\text { Ohio (3), Brandenburg } \\
\text { (1), Derby (1) }\end{array}$ \\
\hline
\end{tabular}

A soroprevalência foi igualmente utilizada em programa de controle implementado na Dinamarca para classificar granja quanto à infecção (Alban et al., 2002). A partir dessa classificação, medidas diferenciadas de monitoramento e intervenção foram tomadas para eliminar granjas classificadas no nível 3 soroprevalência acima de $70 \%$, diminuir o grupo no nível 2 - 30-70\% e alcançar a maioria das granjas no nível $1-<30 \%$. Aplicando-se esse critério de classificação, observa-se que, no presente estudo, a maioria das granjas seria classificada no nível 3 (Fig. 1), considerado o mais crítico em termos de risco para a cadeia de produção.

O ELISA é aplicável para estimar o risco que lotes de animais podem representar para a transmissão do agente ou a contaminação de produtos (Nielsen et al., 1995). Uma elevada soroprevalência pode refletir em infecção em fases iniciais (creche, recria), na terminação ou mesmo decorrer de múltiplas infecções que ocorreram ao longo de todas as fases de criação. Ao lado disso, após a soroconversão, poderá haver a recuperação do animal que se tornará negativo no isolamento de Salmonella sp., persistindo como soropositivo (Lo Fo Wong et al., 2004; van der Gaag et al., 2004). Entretanto, é amplamente aceito que lotes com alta soroprevalência representam um risco para a presença de animais portadores e excretores de Salmonella ao abate (Sorensen et al., 2004; Funk et al., 2005). Essa tendência pôde ser observada também no presente estudo (Fig. 2), em que a maioria dos lotes esteve concentrada na área de soroprevalência e frequência de isolamento acima de 30\%. Apenas um lote apresentou frequência de isolamento acima de $70 \%$ e soroprevalência abaixo de $30 \%$, podendo ser este um caso em que a infecção ocorreu na última semana de terminação ou no período pré-abate. 


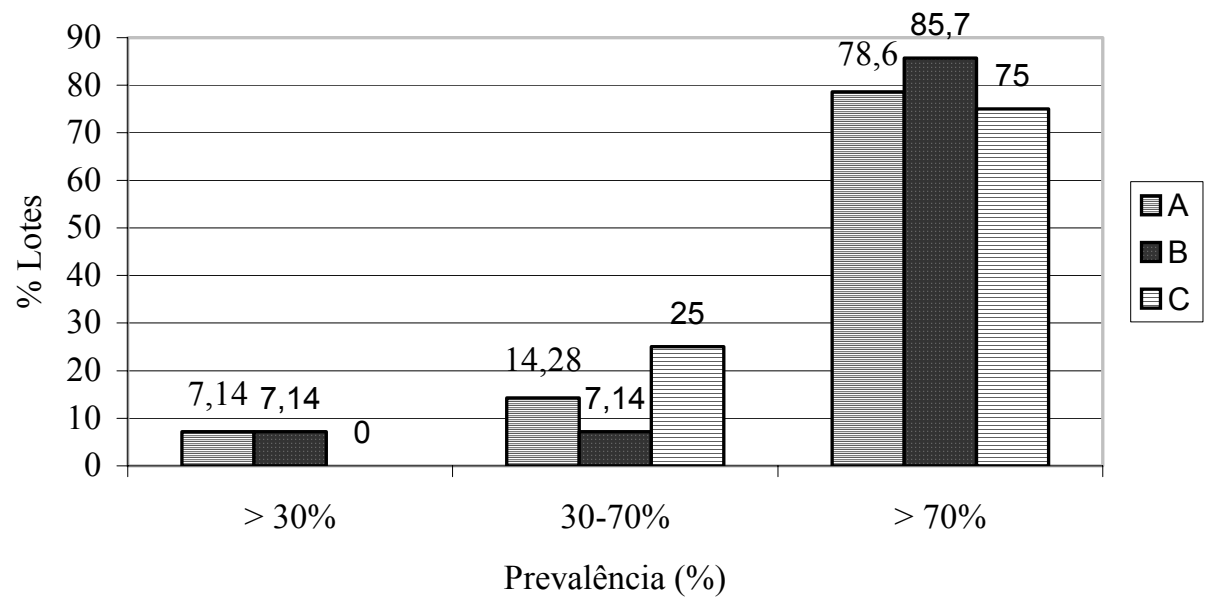

Figura 1. Distribuição de lotes de suínos abatidos em três matadouros-frigoríficos (A, B, C) do sul do Brasil, de acordo com os níveis de prevalência sorológica para Salmonella sp. em 2005.

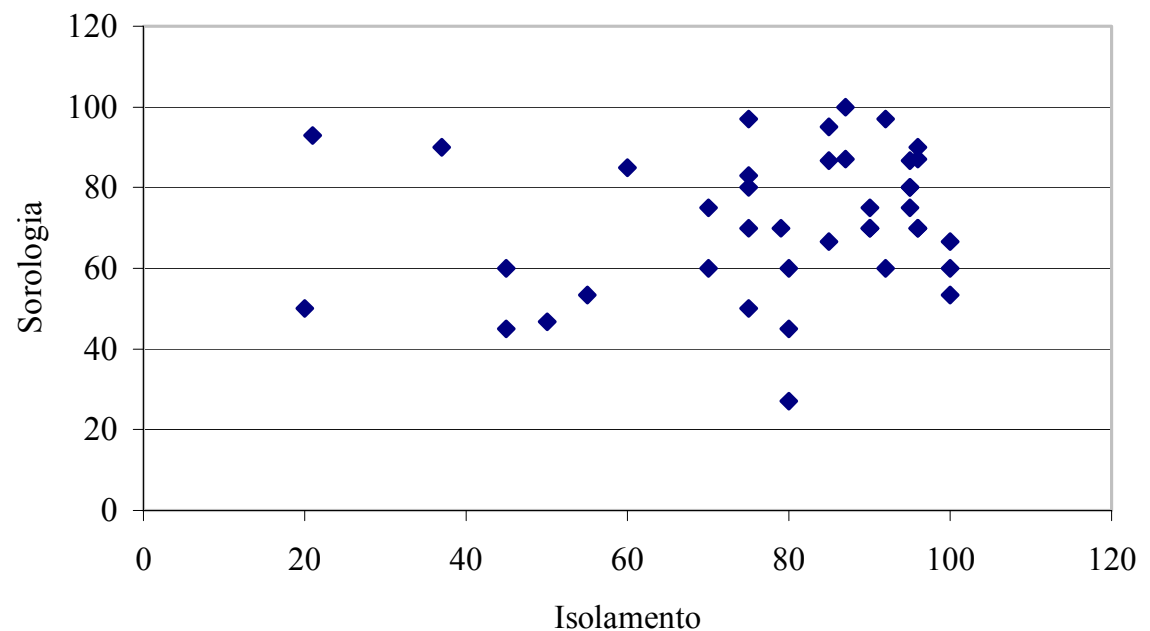

Figura 2. Dispersão de lotes de suínos abatidos em três matadouros - frigoríficos no Rio Grande do Sul, de acordo com a prevalência sorológica e o isolamento de Salmonella spp.

Uma relação direta entre a soroprevalência e o isolamento de Salmonella sp. foi observada quando os resultados foram comparados nos rebanhos do sistema $\mathrm{A}(\mathrm{P}=0,45)$ e $\mathrm{B}(\mathrm{P}=0,33)$, correspondentes a sistemas de integração vertical. Para os rebanhos do sistema $\mathrm{C}$, houve diferença significativa $(\mathrm{P}=0,01)$ entre os parâmetros sorológicos e de isolamento avaliados. Provavelmente esta diferença identificada entre sistemas de produção reflita a maior variabilidade entre idade/fase de infecção nos rebanhos da cooperativa (sistema C). Os associados e granjas independentes da cooperativa não recebem ração formulada, assistência técnica e linhagens genéticas da empresa, e não obedecem a programas de profilaxia e biossegurança como nos sistemas de integração vertical (rebanhos A e B). De fato, no sistema vertical, provavelmente há fatores de risco de infecção comuns às diferentes granjas que compõem o sistema e, portanto, uma certa uniformidade na cadeia de transmissão da infecção nesses casos. 
A presença ao abate de animais positivos no isolamento de Salmonella sp., por sua vez, representa um elevado risco para a ocorrência de contaminação de carcaças e produtos finais, sendo o animal portador considerado o principal introdutor de Salmonella sp. na linha de abate e processamento (Berends et al., 1996). Nesse sentido, investigações já realizadas no Rio Grande do Sul têm demonstrado que a elevada prevalência de animais portadores ao abate implica contaminação de embutidos e cortes de pernil produzidos com a carne desses animais (Castagna et al., 2004).

Com a utilização dos dois instrumentos de análise, testes bacteriológicos e sorológicos, foi identificada a origem da infecção dos rebanhos, por comparação das prevalências encontradas nos lotes abatidos. Em todos os sistemas de produção avaliados, a infecção por Salmonella sp. teve origem preponderantemente nas granjas produtoras de suínos, pois os lotes de animais chegaram ao abate positivos no ELISA. Tendo em vista o crescimento da suinocultura brasileira e a demanda por qualidade, inocuidade e certificação de conformidades de produtos de origem animal, alternativas de controle devem ser implementadas nas granjas produtoras de suínos, a fim de reduzir o número de animais infectados e, por conseguinte, a amplificação da infecção ao longo das fases de produção e a contaminação do produto final.

\section{CONCLUSÕES}

Os resultados de sorologia e isolamento de Salmonella sp obtidos demonstram que a infecção dos suínos abatidos no sul do Brasil ocorre preponderantemente durante o período em que os animais estão na granja. Medidas de controle deverão, portanto, ser direcionadas prioritariamente para essa fase de produção.

\section{AGRADECIMENTOS}

À Dra. Eliane Falavina dos Reis, Departamento de Bacteriologia, Instituto Oswaldo Cruz, pela sorotipificação das amostras. Esse estudo teve auxílio do Conselho Nacional de Pesquisa (P. Schwarz - bolsa de Mestrado, A. Sella e J. Calveyra - bolsa de Iniciação Científica), CAPES (M. Bessa - bolsa de Doutorado) e financiamento do PRODETAB (083-02/01) e Boehringer Ingelheim do Brasil.

\section{REFERÊNCIAS BIBLIOGRÁFICAS}

ALBAN, L.; STEGE, H.; DAHL, J. The new classification system for slaughter-pig herds in the Danish Salmonella surveillance-and-control program. Prev. Vet. Med., v.53, p.133-146, 2002.

ALBAN, L.; STÄRK, K.D.C. Where should the effort be put to reduce the Salmonella presence in the slaughtered swine carcass effectively? Prev. Vet. Med., v.68, p.63-79, 2005.

BAHNSON, P.B.; KIM, J.Y.; WEIGEL, R.M. et al. Association between on-farm and slaughter plant detection of salmonella in market-weight pigs. J. Food Prot., v.68, p.246-250, 2005.

BERENDS, B.R.; URLINGS, H.A.P.; SNIJDERS, J.M.A. et al. Identification and quantification of risk factors in animal management and transport regarding Salmonella spp. in pigs. Food Microbiol., v.30, p.37-53, 1996.

BESSA, M.C.; COSTA, M.; CARDOSO, M. Prevalência de Salmonella sp. em suínos abatidos em frigoríficos do Rio Grande do Sul, Brasil. Pesq. Vet. Bras., v.24, p.80-84, 2004.

CASTAGNA, S.M.F.; SCHWARZ, P.; CANAL, C.W. et al. Prevalência de suínos portadores de Salmonella sp. ao abate e contaminação de embutidos tipo frescal. Acta Sci. Vet., v.32, p.141-147, 2004.

DAVIES, R.H.; DALZIEL, R.; GIBBENS, J.C. et al. National survey for Salmonella in pigs, cattle and sheep at slaughter in Great Britain (1999-2000). J. Appl. Microbiol., v.96, p.750$760,2004$.

FUNK, J.A.; HARRIS, I.T.; DAVIES, P.R. Comparison of fecal culture and Danish MixELISA for determination of Salmonella enterica subsp. enterica prevalence in growing swine. Vet. Microbiol., v.107, p.115-126, 2005.

HARRIS, I.T. Serologic basis for assessment of subclinical Salmonella infection in swine: part I. Swine Health Prod., v.11, p.247-251, 2003.

HURD, H.S., McKEAN, J.D., WESLEY, I.V. et al. The effect of lairage on Salmonella isolation from market swine. J. Food Prot., v.64, p.939944, 2001.

KÄSBOHRER, A.; PROTZ, D.; HELMUTH, R. et al. Salmonella in slaughter pigs of German 
origin: an epidemiological study. Eur. J. Epidemiol., v.16, p.141-146, 2000.

KICH, J.D.; MORES, N.; PIFFER, I. et al. Fatores de risco associados com a prevalência sorológica de Salmonella em granjas comerciais de suínos no sul do Brasil. Cienc. Rural, v.35, p.398-405, 2005.

KICH, J.D.; SCHWARZ, P.; SILVA, L.E. et al. Development and application of an enzymelinked immunosorbent assay to detect antibodies against prevalent Salmonella serovars in swine in southern Brazil. J. Vet. Diagn. Invest., v.19, p.510-517, 2007.

LO FO WONG, D.M.A.; DAHL, J.; WINGSTRAND, A. et al. A European longitudinal study in Salmonella seronegative and seropositive classified finishing pig herds. Epidemiol. Infect., v.132, p.903-914, 2004.

MOUSING, J.; JENSEN, P.T.; HALGAARD, C. et al. Nation-wide Salmonella enterica surveillance and control in Danish slauther swine herds. Prev. Vet. Med., v.53, p.247-261, 1997.

NIELSEN, B.; BAGGESEN, D.; BAGER, F. et al. The serological response to Salmonella serovar Typhimurium and Infantis in experimentally infected pigs. The time course followed with an indirect anti-LPS ELISA and bacteriological examinations. Vet. Microbiol., v.47, p.205-218, 1995.

PADUNGTOD, P.; KANEENE, J.B. Salmonella in food animals and humans in northern Thailand. Int. J. Food Microbiol., v.108, p.346354, 2006

ROSTAGNO, M.H.; HURD, H.S.; MCKEAN, J.D. et al. Preslaughter holding environment in pork plants is highly contaminated with Salmonella enterica. Appl. Environ. Microbiol., v.69, p.4489-4494, 2003.

SILVA, L.E.; GOTARDI, C.P.; VIZZOTO, R. et al. Infecção por Salmonella enterica em suínos criados em um sistema integrado de produção do sul do Brasil. Arq. Bras. Med. Vet. Zootec., v.58, p.455-461, 2006.
SILVA, M.C.; FARIA, G.S.; PAULA, D.A.J. et al. Prevalência de Salmonella sp. em suínos abatidos no Estado do Mato Grosso. Cienc. Rural, v.39, p.266-268, 2009.

SORENSEN, L.; ALBAN, L.; NIELSEN B. et al. The correlation between Salmonella serology and isolation of Salmonella in Danish pigs at slaughter. Vet. Microbiol., v.101, p.131-141, 2004.

SWANENBURG, M.; URLINGS, H.A.P.; SNIJDERS, J.M.A. et al. Salmonella in slaughter pigs: prevalence, serotypes and critical control points during slaughter in two slaughterhouses. Int. J. Food Microbiol., v.70, p.243-254, 2001.

van ALTROCK, A.; SCHUTTE, A.; HIDEBRANT, G. Results of the German investigation in the EU - Project "Salmonella in pork (Salinpork)"- part 1: Investigations in the farm Berl. Munch. Tierarz. Wochensch., v.113, p.191-201, 2000.

van der GAAG, M.A.; VHOS, F.; SAATKAMP, H.W. et al. A state-transition simulation model for the spread of Salmonella in the pork supply chain. Eur. J. Oper. Res., v.156, p.782-798, 2004.

van der WOLF, P.J.; WOLBERS, W.B.; ELBERS, A.R. et al. Herd level husbandry factors associated with the serological Salmonella prevalence in finishing pig herds in The Netherlands. Vet. Microbiol., v.78, p.205219, 2001

VIEIRA-PINTO, M.; TEMUDO, P.; MARTINS, C. Occurrence of Salmonella in the ileum, ileocolic lymph nodes, tonsils, mandibular lymph nodes and carcasses of pigs slaughtered for consumption. J. Vet. Med. B Infect. Dis. Vet. Public Health, v.52, p.476-481, 2005.

WEGENER, H. C.; BAGGESEN, F. Pork as a source of human salmonellosis. In: INTERNATIONAL SYMPOSIUM ON THE EPIDEMIOLOGY E CONTROL OF SALMONELLA IN PORK, 2., 1997, Copenhagen, Proceedings... Copenhagen: [s.n.], 1997. p.3-8. 